\title{
Akar Wangi Institute dengan Pendekatan Permakultur sebagai Dasar Perancangan
}

\author{
Wisnu Sujarwor ${ }^{1}$, Aprodita Emma Yetti ${ }^{2}$ \\ ${ }^{1}$ Program Studi Arsitektur, Fakultas Sains dan Teknologi, Universitas 'Aisyiyah Yogyakarta \\ ${ }^{2}$ Program Studi Arsitektur, Fakultas Sains dan Teknologi, Universitas 'Aisyiyah Yogyakarta \\ Email: Wisnusujarwo7.ws@gmail.com
}

\begin{abstract}
Abstrak
Semin merupakan salah satu Kecamatan di Kabupaten Gunungkidul yang memilikki potensi dengan banyak produk unggulan, diantaranya adalah kerajinan bambu dan akar wangi. Dengan meningkatnya permintaan akan produk tersebut, hal tersebut menimbulkan dampak baik positif maupun negatif. Dampak positifnya adalah meningkatnya lapangan kerja dan kreatifitas masyarakat, sedangkan dampak negatifnya adalah timbulnya masalah lingkungan berkaitan dengan penggunaan sumber daya alam yang tidak diiringi dengan pengetahuan dan kesadaran mengenai kelestarian alam. Selain potensi, Semin juga memilikki isu-isu yang memerlukan penyelesaian seperti sulitnya air di daerah-daerah tertentu, dan juga kurangnya fasilitas umum pendidikan ataupun pusat edukasi. Tantangan desain dalam perancangan ini adalah mewadahi dan meningkatkan potensi Daerah terpilih yang memiliki isu-isu atau permasalahan yang tidak dapat dipisahkan dengan potensi itu sendiri. Perancangan Akar Wangi Institutee dengan pendekatan permakultur diharapkan dapat mewadahi dan meningkatkan potensi, serta mengatasi permasalahan pada Daerah terpilih.
\end{abstract}

Kata Kunci: Kerajinan, Institute, Permakultur

Article history: Received 2020-08-21; Revised 2020-12-14; Accepted 2021-01-14

\section{PENDAHULUAN}

Semin merupakan salah satu dari sekian Kecamatan di Kabupaten Gunungkidul, Provinsi Daerah Istimewa Yogyakarta, Indonesia. Kecamatan ini memliki jarak sekitar 22-kilometer ke arah timur laut dari pusat kota Kabupaten Gunungkidul, yaitu Wonosari. Pusat pemerintahan pada Kecamatan Semin berada di Desa Semin. Kegiatan masyarakat yang dominan di wilayah ini adalah bertani, berternak, dan berkarya dalam bidang kriya. Produk unggulan Kecamatan Semin antara lain akar wangi, kaolin, ukir batu, dan kerajinan. Produk-produk tersebut bahkan sudah diekspor ke mancanegara seperti Amerika, Kuwait, dan Belanda.

Sebagai salah satu produk unggulan Semin, kerajinan yang unik diantaranya kerajinan bambu dan akar wangi. Saat ini, kerajinan-kerajinan ini sangat ramai permintaan sehingga menyebabkan dampak positif dan negatif. Dampak positif dari hal tersebut adalah terciptanya lapangan kerja dan kreatifitas masyarakat, serta meningkatkan daya tarik dan identitas wilayah Semin itu sendiri. Sedangkan dampak negatif yang ditimbulkan adalah pemanfaatan sumber daya alam yang berlebihan, namun kesadaran masyarakat tentang ekosistem dan kelestarian alam yang masih rendah. Selain itu kegiatan kerajinan tersebut juga menghasilkan limbah yang belum diolah secara tepat oleh masyarakat sekitar sehingga menimbulkan isu 
lingkungan. Selain memiliki potensi, Semin juga memiliki isu-isu yang memerlukan penyelesaian seperti sulitnya air pada musim kemarau di desadesa tertentu, dan minimnya fasilitas umum pendidikan seperti perpustakaan dan pusat edukasi. Dengan potensi, budaya, keadaan alam, dan masyarakat yang ada, seharusnya Semin dapat menjadi wilayah yang asri, kreatif, berpendidikan, bernilai ekonomi tinggi, dan sadar akan pentingnya kelestarian alam.

Salah satu cara untuk mewujudkan Daerah Semin yang asri, kreatif, berpendidikan, bernilai ekonomi tinggi, dan sadar akan kelestarian alam adalah dengan cara mendesain suatu bangunan dan lansekap untuk mewadahi potensi, merespon isu-isu daerah, dan juga mengedukasi masyarakat berupa "Bamboo Akar Wangi Institutee". Permaculture yang dapat diartikan sebagai permanent culture merupakan hal-hal yang berkaitan dengan peningkatan pelestarian dan mendukung kondisi lingkungan yang baik dengan dasar kerjasama budaya dan lingkungan lokal sehingga dapat tumbuh bersama. Permaculture merupakan pendekatan yang dirasa paling tepat guna mewujudkan desain yang mengintegrasi antara alam dan masyarakat secara berkelanjutan, dikarenakan dalam pendekatannya permaculture itu sendiri memilikki indikator yang erat dengan alam dan masyarakat.

Tunjuan penelitian ini adalah untuk menghasilkan rancangan untuk mewadahi potensi, merespon isu daerah dan juga mengedukasi masyarakat dengan pendekatan permaculture sehingga terwujud Daerah Semin yang asri, kreatif, berpendidikan, bernilai ekonomi tinggi, dan sadar akan kelestarian alam, yaitu Akar Wangi Institute.

\section{TINJAUAN PUSTAKA}

Yudha (2017) memaparkan bahwa permaculture memiliki dua arti, yang pertama adalah permanent agriculture, dan yang kedua adalah permanent culture. Perbedaannya adalah permanent agriculture merupakan hal-hal yang berkaitan dengan peternakan dan pertanian yang dapat dikelola untuk masa mendatang dengan sifat berkelanjutan sehingga kualitas peternakan dan pertanian dapat terus mempertahankan kualitasnya dengan baik. Sedangkan permanent culture merupakan hal-hal yang berkaitan dengan peningkatan pelestarian dan mendukung kondisi lingkungan yang baik dengan dasar kerjasama budaya dan lingkungan lokal sehingga dapat tumbuh bersama.

Sidiq (2016) memaparkan bahwa permaculture memilikki beberapa prinsip utama diantaranya:

(1) Memelihara bumi

(2) Memelihara masyarakat

(3) Mendaur ulang kelebihan hasil

Konsep utama permaculture adalah pemaksimalan hubungan harmonis yang saling menguntungkan antara komponen lingkungan dengan masyarakat, serta menghasilkan desain yang tersinergi. Permaculture juga memiliki 12 prinsip dalam perancangannya, diantaranya sebagai berikut: hargai keaneka ragaman, tanpa sampah, hemat energi, hasil panen, pola 
yang detail, solusi sederhana, timbal balik, interaksi, menyatukan, gunakan tepian, hargai sumber daya, dan respon terhadap perubahan.

\section{PROSES RANCANG DAN EKSPLORASI}

Konsep dari perancangan Akar Wangi Institute adalah perancangan dengan pendekatan permakultur sebagai dasar perancangan. Nama Akar Wangi Institute sendiri berasal dari potensi yang dimiliki oleh daerah yaitu kerajinan akar wangi. Selain mewadahi potensi kerajinan akar wangi, perancangan ini juga mewadahi kerajinan lain yaitu kerajinan bambu. Perancangan ini juga diharapkan dapat memberi solusi dari isu-isu yang ada di daerah site terpilih, baik dari segi lingkungan, edukasi, sosial-budaya, maupun ekonomi.

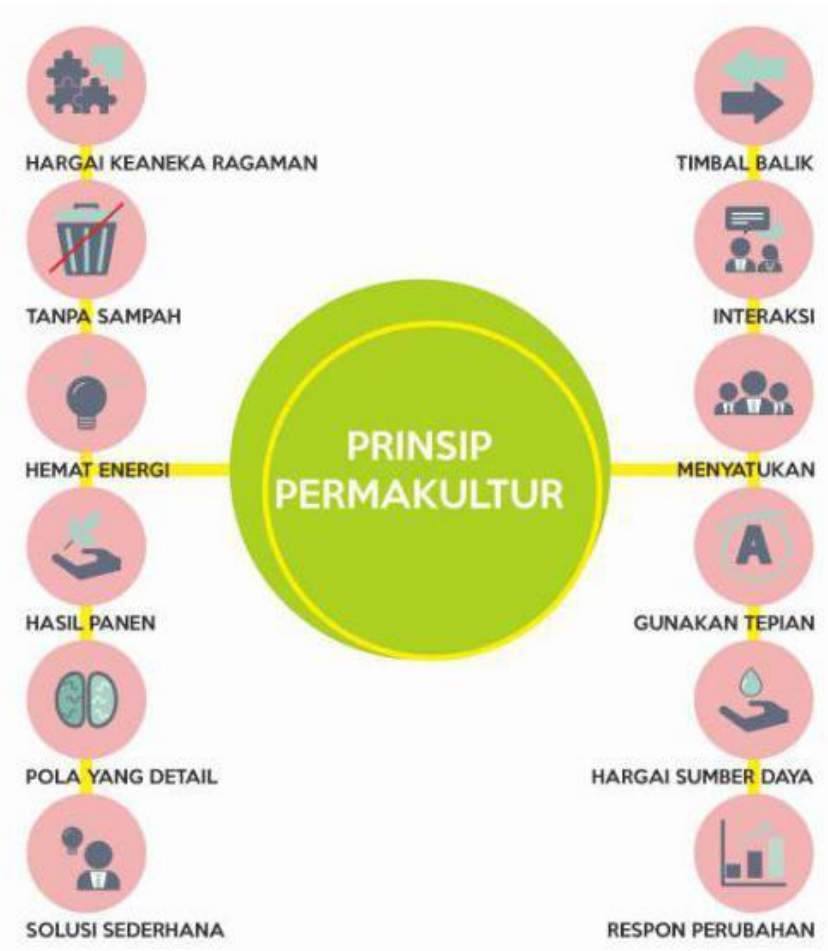

Gambar 1. Prinsip Permakultur

Dari prinsip-prinsip tersebut, dapat diterapkan dalam perancangan, sebagai berikut: 


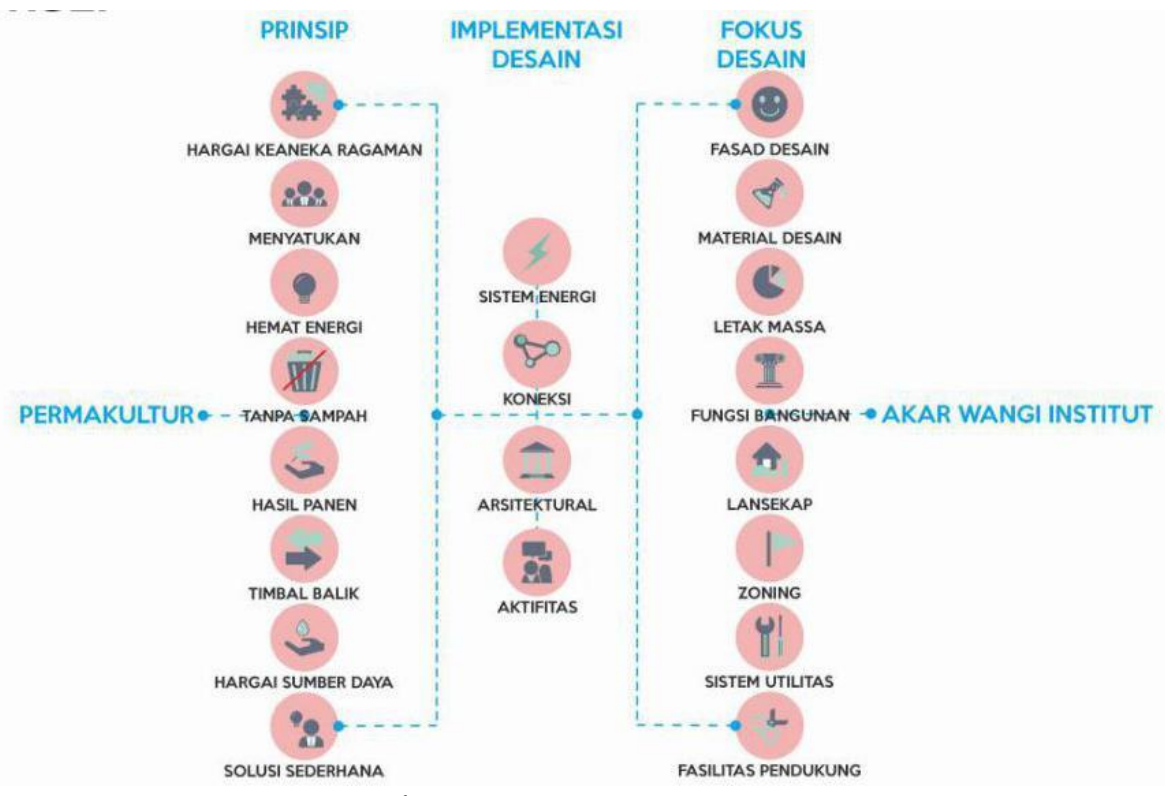

Gambar 2. Diagram Konsep
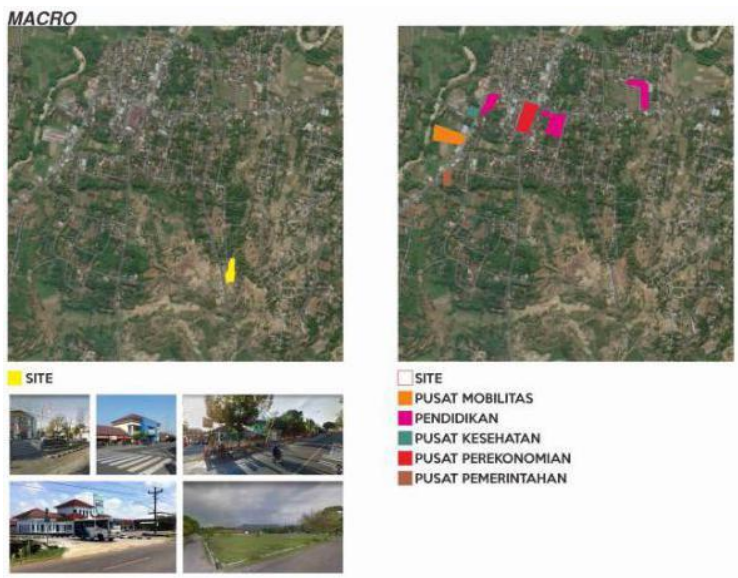

PUSAT MOBLITAS

- PENDIDIKAN

- PUSAT PEREKONOMIAN

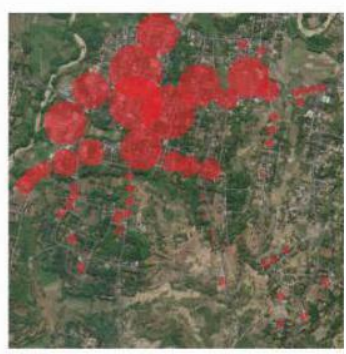

tINGKAT AKTIFTAS

PUSAT PEMERINTAHAN

Gambar 3. Data Macro

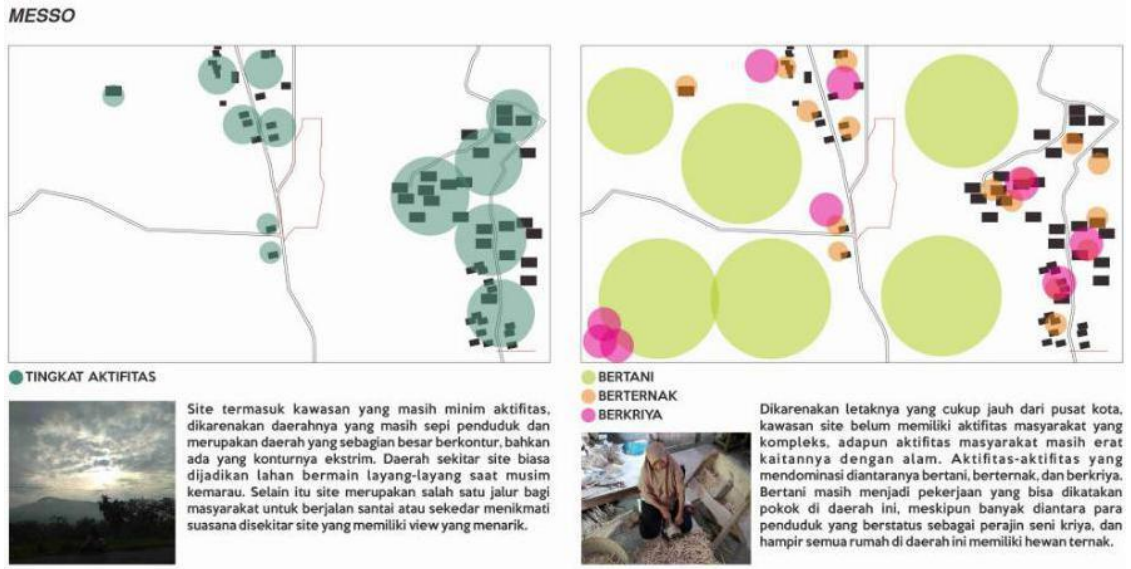

Gambar 4. Data Messo 


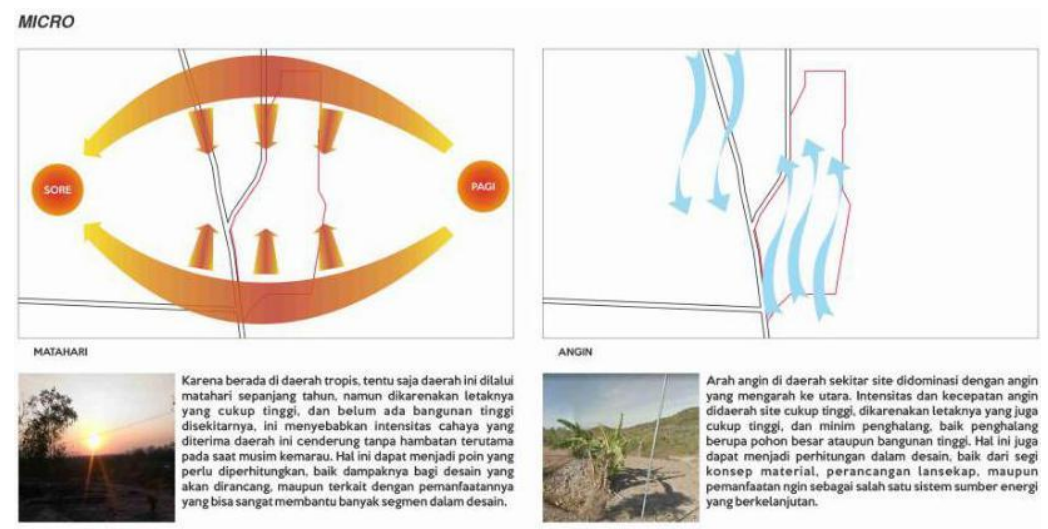

Gambar 5. Data Micro

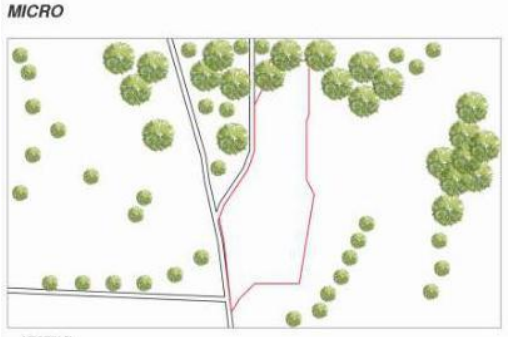
VEGETAS
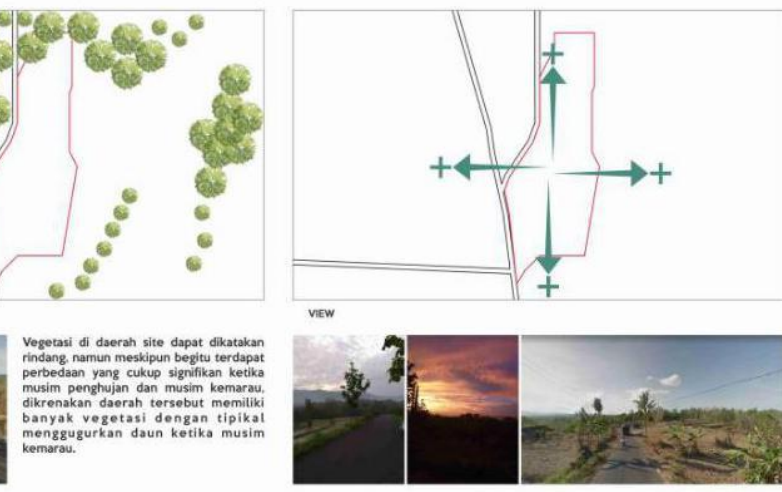

Gambar 6. Data Micro
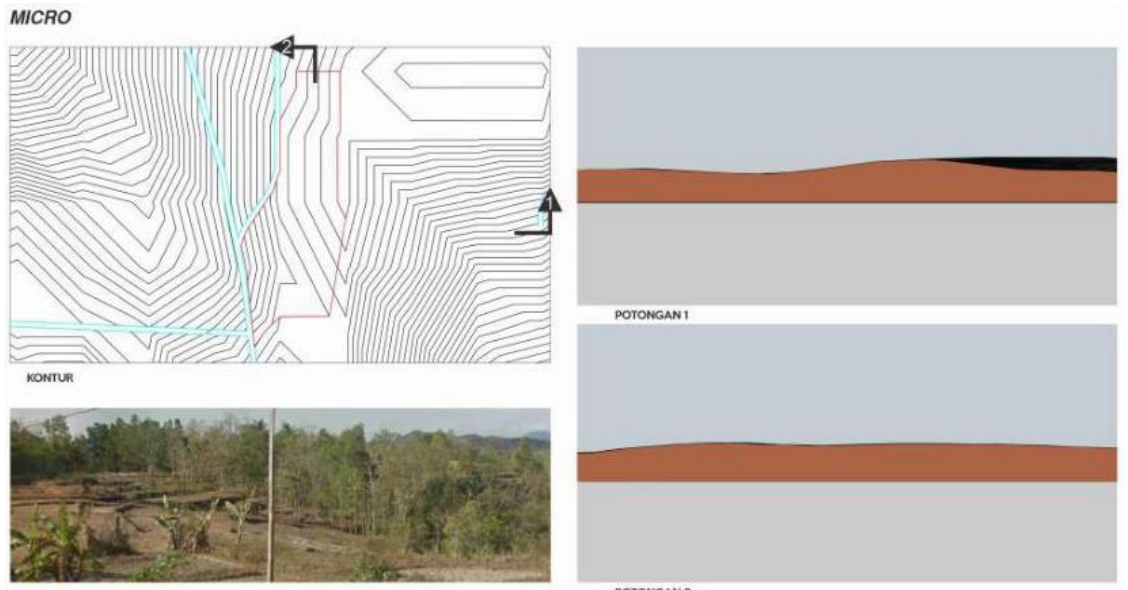

Gambar 7. Data Micro 


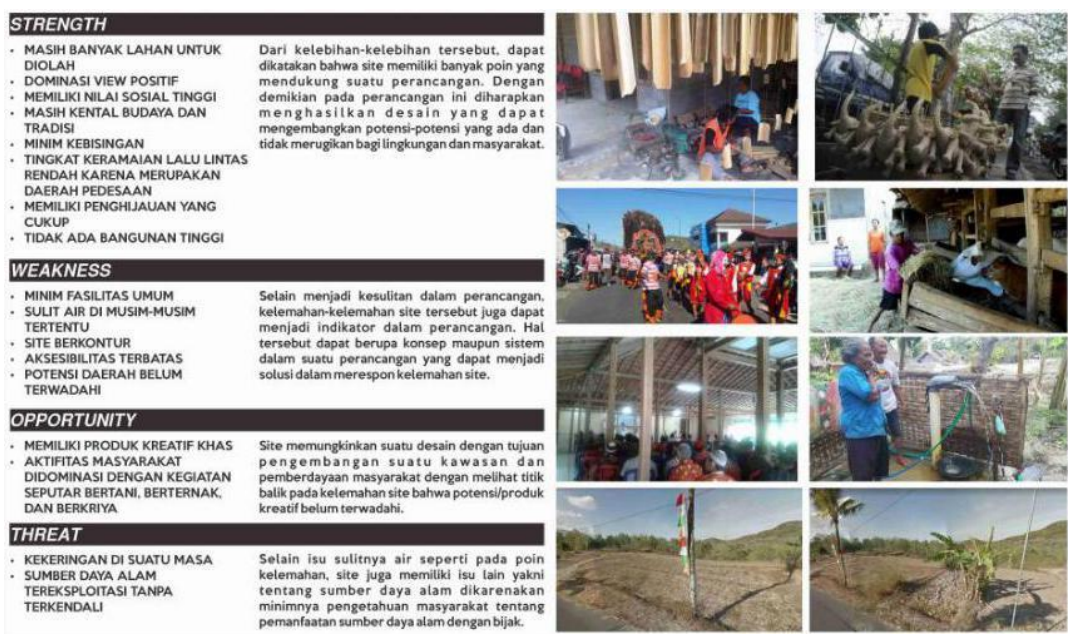

Gambar 8. Analisis Data Lapangan

\section{Tabel 1. Analisa Pengguna}

\begin{tabular}{|c|c|c|c|c|}
\hline NO & DAFTAR PENGGUNA & JENIS AKTIFITAS & RUANG & JUMLAH \\
\hline 1 & PENGUNJUNG & $\begin{array}{ll}\text { - } & \text { DATANG } \\
\text { - } & \text { REGISTRASI } \\
\text { - } & \text { KUNJUNGAN } \\
\text { - } & \text { WORKSHOP } \\
\text { - } & \text { MAKAN-MINUM } \\
\text { - } & \text { BELANJA } \\
\text { - } & \text { KE TOILET } \\
\text { - } & \text { BELAJAR }\end{array}$ & $\begin{array}{ll}\text { - } & \text { AREA PARKIR } \\
\text { - } & \text { SHELTER } \\
\text { : } & \text { RUANG REGISTRASI } \\
\text { - } & \text { SHOWROOM } \\
\text { - } & \text { RUANG WORKSHOP } \\
\text { - } & \text { WARUNG/KANTIN } \\
\text { - } & \text { TOILET } \\
\text { - } & \text { PERPUSTAKAAN }\end{array}$ & $\begin{array}{l}\cdot 1 \\
\cdot-1 \\
\cdot 1 \\
\cdot 1 \\
\cdot 1 \\
\cdot 1 \\
\cdot 1 \\
\cdot 1 \\
\cdot 1\end{array}$ \\
\hline 2 & PENGELOLA & $\begin{array}{ll}* & \text { MENGELOLLA AREA AREA } \\
\text { - } & \text { TRANSIT } \\
\text { - } & \text { ISTIRAHAT } \\
\text { * } & \text { KE TOILET } \\
\text { - } & \text { RAPAT }\end{array}$ & $\begin{array}{ll}\text { - } & \text { RUANG PENGELOLA } \\
\text { - } & \text { RUANG PERALATAN } \\
\text { - } & \text { TOILET PENGELOLA } \\
\text { - } & \text { RUANG RAPAT } \\
\text { - } & \text { AULA } \\
\text { - } & \text { RUANG PENGELOLAAN } \\
& \text { LIMBAH }\end{array}$ & 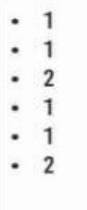 \\
\hline 3 & MASYARAKAT & $\begin{array}{ll}\text { - } & \text { BERJUALAN } \\
\text { - } & \text { BERCOCOK TANAM } \\
\text { - } & \text { BERKRIYA } \\
\text { - } & \text { BERTERNAK } \\
\text { - } & \text { BELAJAR } \\
\text { - } & \text { ISTIRAHAT }\end{array}$ & $\begin{array}{ll}\text { - } & \text { WARUNG/KANTIN } \\
\text { - } & \text { LAHAN BERCOCOK TANAM } \\
\text { - } & \text { KANDANG } \\
\text { - } & \text { RUANG WORKSHOP } \\
\text { - } & \text { LUMBUNG PANEN } \\
\text { - } & \text { RUANG PENGELOLAAN } \\
& \text { UMMBAH } \\
\text { - } & \text { RUANG ISTIRAHAT } \\
\text { - } & \text { PERPUSTAKAAN } \\
\text { - } & \text { TOILET }\end{array}$ & 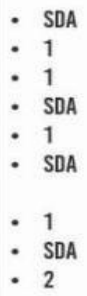 \\
\hline
\end{tabular}




\section{HASIL PERANCANGAN}

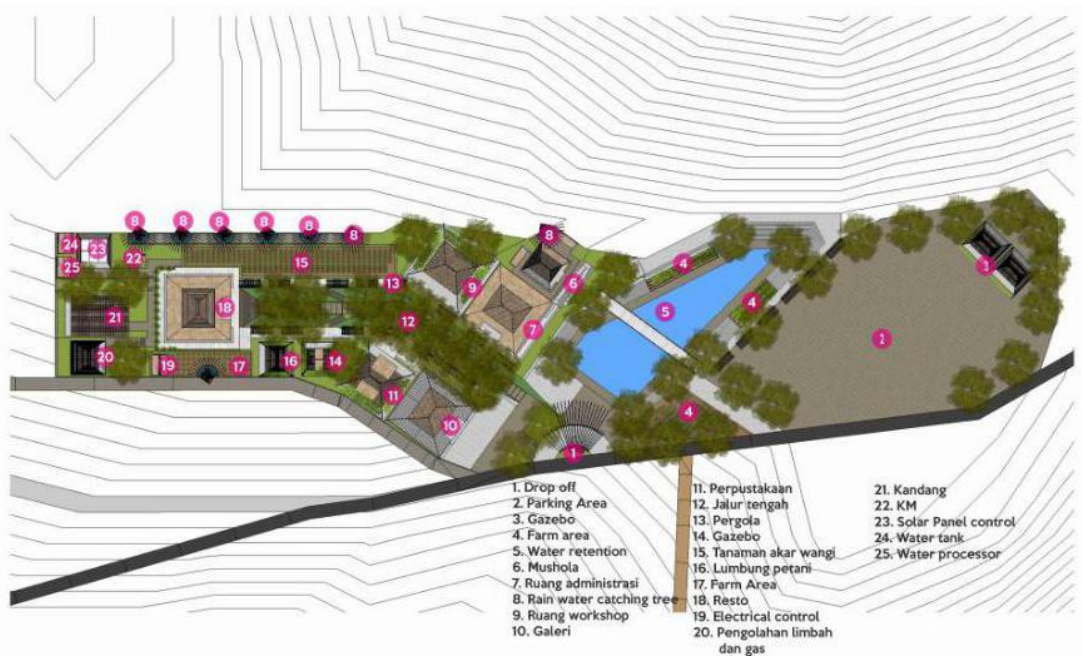

Gambar 9. Siteplan

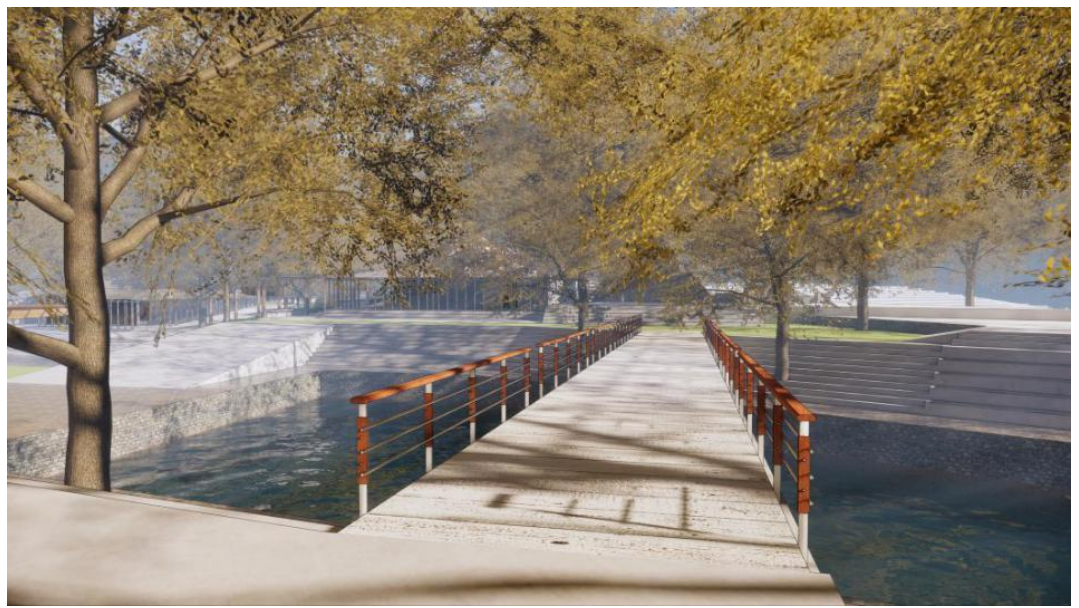

Gambar 10. Massing

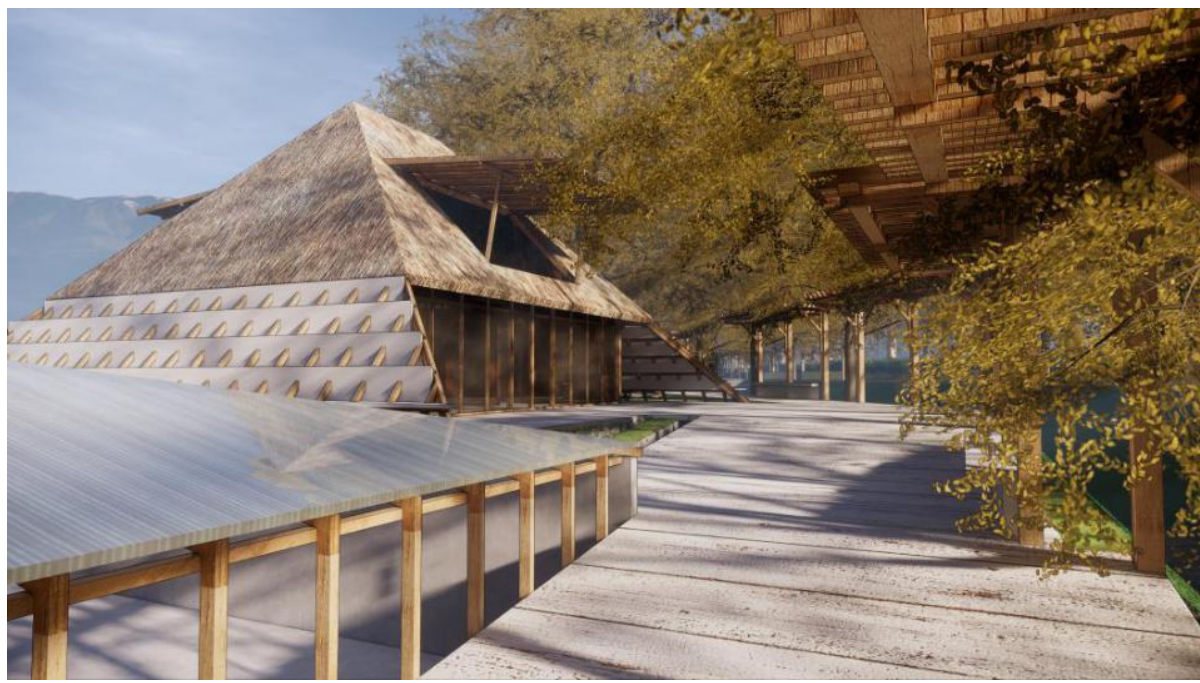

Gambar 11. Massing 


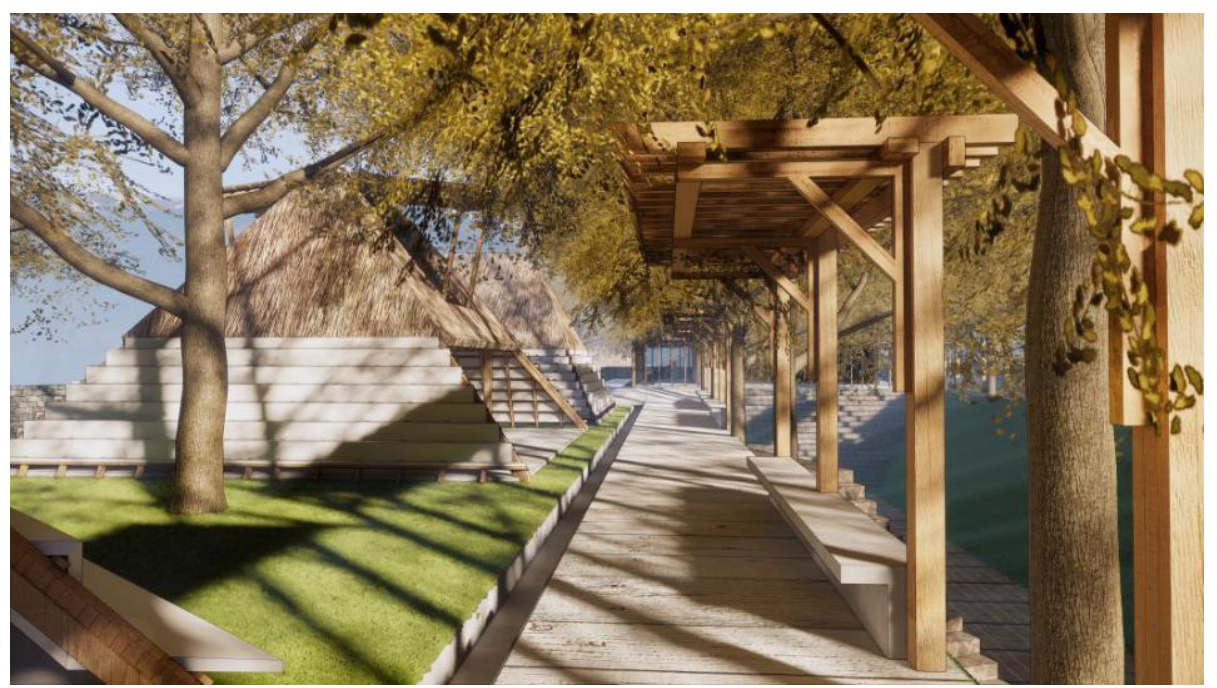

Gambar 12. Massing

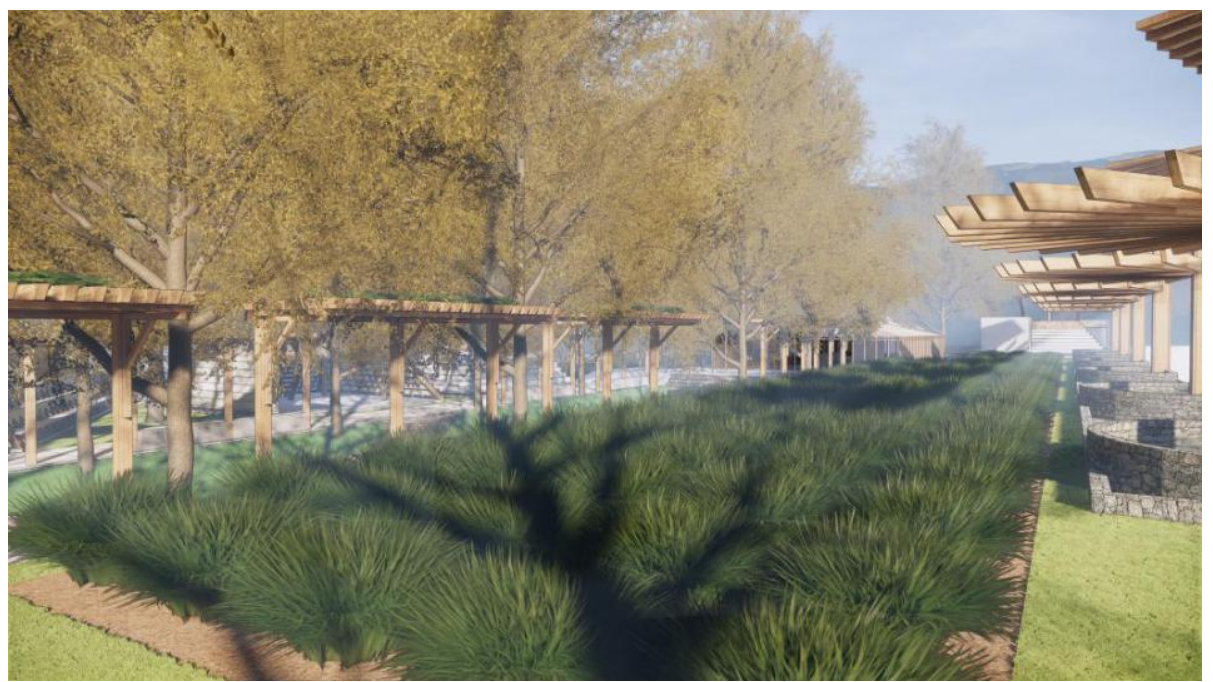

Gambar 13. Massing

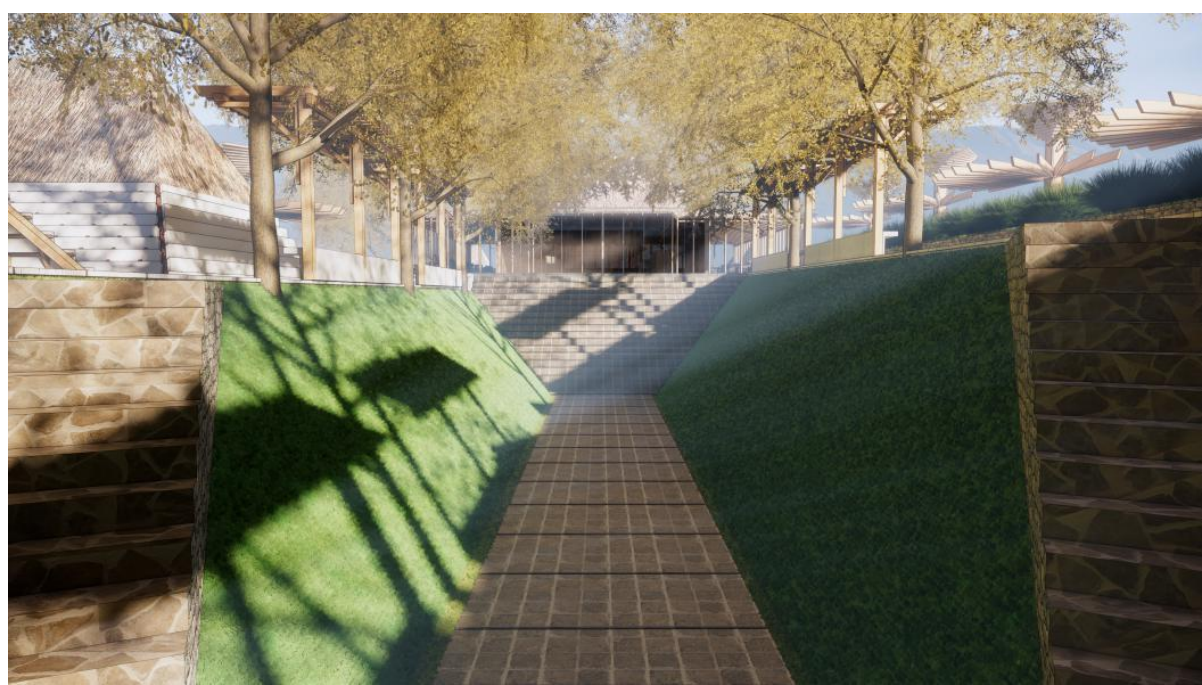

Gambar 14. massing 


\section{KESIMPULAN}

Daerah Semin merupakan salah satu daerah yang memproduksi kerajinan bambu dan akar wangi. Dampak positif dari adanya kerajinan tersebut adalah meningkatnya lapangan kerja dan kreatifitas masyarakat, sedangkan dampak negatifnya adalah timbulnya masalah lingkungan berkaitan dengan penggunaan sumber daya alam yang tidak diiringi dengan pengetahuan dan kesadaran mengenai kelestarian alam. Tantangan desain dalam perancangan ini adalah mewadahi dan meningkatkan potensi Daerah terpilih yang memiliki isu-isu atau permasalahan yang tidak dapat dipisahkan dengan potensi itu sendiri. Perancangan Akar Wangi Institutee dengan pendekatan permakultur diharapkan dapat mewadahi dan meningkatkan potensi, mewadahi aktifitas, meningkatkan ekonomi, meningkatkan pedidikan, serta menjaga pelestarian dengan dasar perancangan yang tepat. Tentunya ketika potensi manusia bersinergi dengan alam, harapan terbesar adalah nilai ekonomi dan pendikan yang tinggi, lestari dan berkelanjutan.

\section{DAFTAR RUJUKAN}

Sidiq, A. T. (2016). Pengembangan Kampung Baratan Boyolali Sebagai Pusat Edukasi Permaculture Dan Ekowisata Agraris. Universitas Muhammadiyah Surakarta: 7

Yudha, P. A. (2017). Sekolah Alam Di Dusun Magersari Tulungagung Dengan Konsep Permakultur. Jurnal Mahasiswa Jurusan Arsitektur Universitas Brawijaya, $\mathrm{V}(2): 3$ 